\title{
A novel control strategy based on a look-up table for optimal operation of MTDC systems in post-contingency conditions
}

Seyed Mohsen Alavi and Reza Ghazi

\begin{abstract}
Multi terminal VSC-HVDC systems are a promising solution to the problem of connecting offshore wind farms to AC grids. Optimal power sharing and appropriate control of DC-link voltages are essential and must be maintained during the operation of VSC-MTDC systems, particularly in post-contingency conditions. The traditional droop control methods cannot satisfy these requirements, and accordingly, this paper proposes a novel centralized control strategy based on a look-up table to ensure optimal power sharing and minimum DC voltage deviation immediately during post-contingency conditions by considering converter limits. It also reduces destructive effects (e.g., frequency deviation) on onshore AC grids and guarantees the stable operation of the entire MTDC system. The proposed look-up table is an array of data that relates operating conditions to optimal droop coefficients and is determined according to N-1 contingency analysis and a linearized system model. Stability constraints and contingencies such as wind power changes, converter outage, and DC line disconnection are considered in its formation procedure. Simulations performed on a 4-terminal VSC-MTDC system in the MATLAB-Simulink environment validate the effectiveness and superiority of the proposed control strategy.
\end{abstract}

Keywords: Optimal power sharing, DC voltage deviation, Adaptive droop control, Multi-terminal HVDC (MTDC), Voltage source converter (VSC)

\section{Introduction}

Renewable energy sources (RESs), and particularly offshore wind farms (OWFs), have started to play a principal role in power systems [1-4]. Accordingly, multi-terminal HVDC (MTDC) systems have been introduced to exchange power between adjacent AC systems and eliminate capacitive current in power transmission from OWFs [5]. The development of MTDC systems has been facilitated by advances in power semiconductor switches, voltage source converters (VSCs), current source converters (CSCs), and DC breakers [6]. The North Sea Super Grid (NSSG) and Atlantic Wind Connection (AWC) are the most important examples of the

*Correspondence: rghazi@um.ac.ir

Department of Electrical Engineering, Ferdowsi University of Mashhad, Mashhad, Iran
MTDC system concept [7, 8]. Converters are the backbone of the MTDC systems structure [9], and the ability to reverse power direction without changing the DC voltage polarity and independent control of active and reactive power by VSCs make them more suitable for MTDC systems than CSCs $[10,11]$.

DC voltage control and proper power sharing in postcontingency conditions are some of the main challenges of MTDC systems [12], while the master-slave, voltage margin, and voltage droop methods are the three basic control schemes [13]. The master-slave method ensures accurate power sharing, though it has disadvantages such as the need for a high-rating master converter and low reliability $[14,15]$. The voltage margin method is an extension of the master-slave method in that it changes the mode of the master converter from constant-voltage to constant-power when it interrupts or reaches its 
limit. This method improves reliability but causes voltage stress on the converters [16-18]. The main idea of the voltage droop method is based on frequency regulation in AC systems [19]. In this method, instead of one converter, several converters are responsible for DC voltage regulation. The high reliability of this method makes it the desirable choice. The operating principles and different kinds of developed droop control are presented in [20-26].

Adaptive droop coefficients considerably improve the performance of voltage droop control. In [27], they are proposed based on the normalized available headroom of converters while the DC voltage is ignored. In [28], the voltage performance index is recommended with available headroom of VSCs to prevent steady-state and transient voltage deviations, whereas reference [29] introduces droop coefficients as variable resistors to reduce power losses without considering active power and DC voltage deviations. Adaptive droop coefficients based on the linearized model of systems dynamics (such as the DC grid, AC grid, filters, and internal current controllers) are proposed in [30], though its weakness is the complexity of calculations in large girds. In [31], droop coefficients are adjusted according to an adaptive network-based fuzzy inference system (ANFIS) to reduce the effect of frequent fluctuations in renewable energy generation on power distribution and DC voltage deviations. In [32], adaptive droop coefficients are recommended based on fuzzy logic and the tradeoff between power sharing and DC voltage regulation, while in [33], they are adjusted based on the voltage and power deviations from nominal values to prevent the converters from hitting their limits in post-contingency conditions. Reference [34] proposes adaptive droop coefficients based on the loading of VSCs and desired DC voltage to prevent converters from exceeding their limits in post-contingency conditions, whereas in [35], droop coefficients are proposed based on over and under voltage containment reserves to guarantee voltage stability in the MTDC grid.

Reference [36] introduces a local power index between adjacent converters to achieve accurate power sharing and increase stability in the presence of communication latency. A coordinated control strategy based on adaptive droop coefficients is proposed in [37] to realize a faster dynamic response and a reasonable power distribution. A hierarchical control method is proposed in $[38,39]$ to update droop coefficients based on optimal power flow (OPF). However, the strategy involves time-consuming calculations and affects the stability of the system. Reference [40] develops a control strategy consisting of a linear quadratic controller and adaptive droop control. It improves the stability in post-contingency conditions and prevents the DC voltages of VSC stations from reaching their limits. Reference [41] uses a secondary control layer based on a consensus algorithm between adjacent converters to adjust adaptive droop coefficients considering the tradeoff between voltage regulation and power sharing.

Optimal operation of an MTDC system considering converter limits in the first control layer immediately during post-contingency conditions is ignored in the work previously cited. This may cause destructive effects on the neighboring AC grids (such as frequency deviation) and on stable operation of the MTDC system while trying to determine the optimal droop coefficients in the secondary control layer. Accordingly, a novel centralized adaptive droop control strategy is proposed to address this problem, in which a look-up table containing optimal droop coefficients based on the linearized system model and prediction of N-1 contingency is used. Thus, optimal droop coefficients are selected from the look-up table according to the contingencies that occurred and immediately applied to the VSCs for use in the first control layer. The novelty and distinguishing advantages of this method are:

- In the post-contingency conditions, optimal power sharing occurs immediately without the need for secondary control layer.

- DC voltage deviations are minimized.

- Active power and DC voltage of all VSCs remain within their ratings in the post-contingency conditions.

- The various contingencies such as wind power changes, converter outage, and DC line disconnection are considered.

- The maximum output power of OWFs is utilized without any curtailment.

- The stability constraints are considered in the proposed optimization problem to guarantee the stable operation of the MTDC system.

- The linearized system model reduces the computational time for the formation procedure of the lookup table.

In Sect. 2, the system components and control structure of the VSCs are presented. Traditional droop and the proposed adaptive droop control strategy are described in Sect. 3. In Sect. 4, the proposed control strategy is applied to a 4-terminal VSC-MTDC system in MATLAB/Simulink and compared with traditional droop control methods to validate its effectiveness. Finally, the conclusions are given in Sect. 5. 


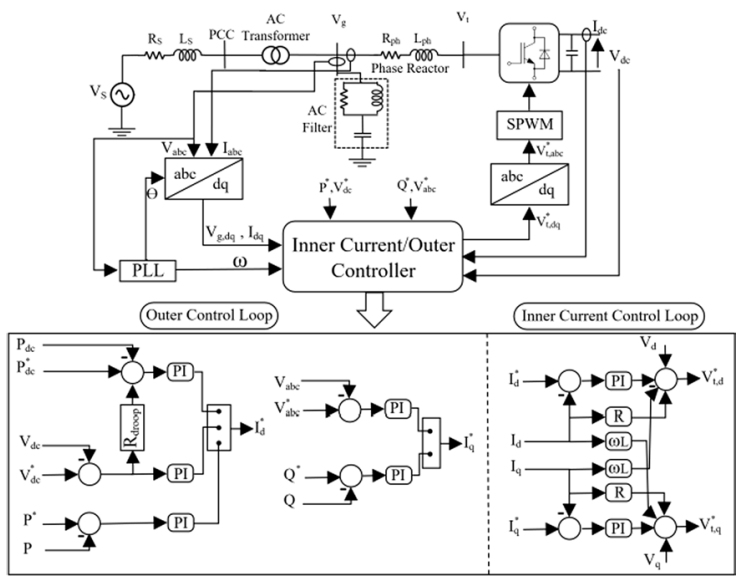

Fig. 1 Single line diagram of the grid-connected VSC station and its control structure

\section{Control of VSC-MTDC system}

The single line diagram of the grid-connected VSC station is shown along with its control scheme in Fig. 1. A Thevenin equivalent circuit of the $A C$ grid $\left(V_{S}\right.$, $\left.\mathrm{Z}_{\mathrm{S}}=\mathrm{R}_{\mathrm{S}}+\mathrm{j} \omega \mathrm{L}_{\mathrm{S}}\right)$ is connected to the VSC by a transformer, $\mathrm{AC}$ filter, and a phase reactor.

The control configuration of the VSC station considering the vector method has two sections: the inner current and the outer controller. The vector method can control the active and reactive power separately through Park's transformation [42]. The inner current controller is implemented based on a dynamic model of the system in the $d-q$ frame, which is expressed by:

$$
\left[\begin{array}{c}
V_{t, d} \\
V_{t, q}
\end{array}\right]-\left[\begin{array}{c}
V_{g, d} \\
V_{g, q}
\end{array}\right]=R\left[\begin{array}{c}
I_{d} \\
I_{q}
\end{array}\right]+L \frac{d}{d t}\left[\begin{array}{c}
I_{d} \\
I_{q}
\end{array}\right]+\omega L\left[\begin{array}{cc}
0 & -1 \\
1 & 0
\end{array}\right]\left[\begin{array}{c}
I_{d} \\
I_{q}
\end{array}\right]
$$

where $\mathrm{R}$ and $\mathrm{L}$ refer to resistance and inductance of the phase reactor, and $\omega$ is the angular frequency measured by the phase-locked loop (PLL). The active and reactive power through decoupled current control is obtained by:

$$
\left\{\begin{array} { l } 
{ P = V _ { d } I _ { d } + V _ { q } I _ { q } } \\
{ Q = V _ { q } I _ { d } - V _ { d } I _ { q } }
\end{array} | _ { p u } \stackrel { V _ { q } = 0 } { \longrightarrow } \left\{\left.\begin{array}{l}
P=V_{d} I_{d} \\
Q=-V_{d} I_{q}
\end{array}\right|_{p u}\right.\right.
$$

Synchronizing the $\mathrm{d}$-axis with the AC voltage phase by the PLL makes $\mathrm{V}_{\mathrm{q}}=0$ and thus simplifies (2). Therefore, active and reactive power can be controlled independently with proper set-points of the d-axis current reference $\left(\mathrm{I}_{\mathrm{d}}^{*}\right)$ and the $\mathrm{q}$-axis current reference $\left(\mathrm{I}_{\mathrm{q}}^{*}\right)$.

The proposed method uses PI controllers, though other control designs such as sliding mode control (SMC) can also be used [43]. The outer control loop can control either active power or DC voltage to provide $\mathrm{I}_{\mathrm{d}}^{*}$ with voltage, power, and droop control modes. It can also provide $\mathrm{I}_{\mathrm{q}}^{*}$ by controlling reactive power or $\mathrm{AC}$ voltage.

\section{The proposed control strategy}

Droop control can be implemented in two forms: current-based (I-V characteristic curve), and power-based ( $\mathrm{P}-\mathrm{V}$ characteristic curve) which is used in this paper [44]. Accurate power sharing in droop control, regardless of DC line resistances and system structure, occurs by common voltage feedback, known as Pilot Voltage Droop (PVD) [45]. Accordingly, the proposed control method uses common voltage feedback in the presence of high-bandwidth communication.

Optimal power sharing should be maintained as much as possible with minimum variation to minimize the negative effects of disturbances on neighboring $\mathrm{AC}$ grids (e.g., frequency deviation) during post-contingency conditions. The optimal droop coefficients satisfy this purpose, while also minimizing the DC voltage variation and maintaining all converters (with or without droop control mode) within their limits. They are determined based on the initial loading of converters, the stability constraint, and converter limitations by linearizing the system around the steady-state operating point in various contingencies.

The optimal droop coefficients are stored in the look-up table to be used immediately in the first control layer after detection of disturbances by the central controller. The proposed look-up table is an array of data that relates input values (operating conditions) to output values (optimal droop coefficients). As a result, the processing time is minimized by retrieving a set of values from memory instead of online calculations. Figure 2 shows the $\mathrm{P}-\mathrm{V}$ droop characteristic curve and the modified power control loop considering the proposed method.

$P_{n}$ and $V_{n}$ are the rated power and voltage of the converter. The central controller detects disturbances through online monitoring of the active power $\left(\mathrm{P}_{\mathrm{i}}\right)$ and DC voltage $\left(\mathrm{V}_{\mathrm{i}}\right)$ of the VSC stations. Droop coefficients $\left(\mathrm{R}_{\text {droop }}\right)$ are inversely related to $\mathrm{DC}$ voltage deviation. Therefore, they can be increased to minimize DC voltage deviation, though high droop coefficients reduce stability. To overcome this drawback, they are limited to the maximum droop coefficients $\left(R_{i, \max }\right)$, which are determined based on small-signal stability analysis of the VSC-MTDC system [21, 27, 46]. Accordingly, the differential-algebraic equations (DAEs) of the system are linearized around the operating point and expressed in state-space form by:

$$
\Delta \dot{X}=A \Delta X+B \Delta U
$$


where $\Delta \mathrm{X}, \Delta \mathrm{U}, \mathrm{A}$, and $\mathrm{B}$ are the state-vector, input-vector, state-matrix, and input-matrix, respectively. The maximum droop coefficients can be increased until all eigenvalues remain in the left half of the complex plane to ensure system stability.

The derivative of the power flow equations with respect to the voltage vector $(\mathrm{V})$ results in the Jacobian matrix, which is expressed by:

$$
\begin{gathered}
\left\{\begin{array}{c}
P=V \odot(Y V) \\
J=\partial P / \partial V
\end{array} \rightarrow J=\operatorname{diag}(V) Y+\operatorname{diag}(Y V)\right. \\
\Rightarrow J=\left[\begin{array}{ccccc}
\partial P_{1} / \partial V_{1} & \ldots & \partial P_{1} / \partial V_{m} & \ldots & \partial P_{1} / \partial V_{n} \\
\vdots & \ddots & \vdots & \ddots & \vdots \\
\partial P_{m} / \partial V_{1} & \ldots & \partial P_{m} / \partial V_{m} & \ldots & \partial P_{m} / \partial V_{n} \\
\vdots & \ddots & \vdots & \ddots & \vdots \\
\partial P_{n} / \partial V_{1} & \ldots & \partial P_{n} / \partial V_{m} & \ldots & \partial P_{n} / \partial V_{n}
\end{array}\right]
\end{gathered}
$$

where $\mathrm{P}$ and $\mathrm{Y}$ refer to the active power vector and admittance matrix of the DC grid. The symbol $\odot$ is the Hadamard product operator.

The formation procedure of the look-up table according to $\mathrm{N}-1$ contingency is presented in the following sections. It is to be noted that converters ' $1: \mathrm{m}$ ' and ' $\mathrm{m}+1: \mathrm{n}$ ' operate in droop and constant power modes, respectively.

\subsection{Wind power changes}

The system equations during wind power changes $\left(\Delta \mathrm{P}^{*}\right)$ are expressed by:

$$
\begin{aligned}
& \left\{\begin{array}{l|l}
\Delta P_{i}=-\alpha R_{i} \Delta V_{1} & \left.\begin{array}{l}
\Delta P_{m+1}=\Delta P^{*} \\
\Delta P_{i}=\sum_{j=1}^{n} J_{i, j} \Delta V_{j}
\end{array}\right|_{i=1: n} \begin{array}{l}
R_{i}=0 \\
i \geq m+1
\end{array}
\end{array}\right. \\
& {\left[\begin{array}{c}
\Delta V_{1} \\
\Delta V_{2} \\
\vdots \\
\Delta V_{m} \\
\Delta V_{m+1} \\
\vdots \\
\Delta V_{n}
\end{array}\right]=\underbrace{\left[\begin{array}{cccc}
J_{1,1}+\alpha R_{1} & J_{1,2} & \cdots & J_{1, n} \\
J_{2,1}+\alpha R_{2} & J_{2,2} & \cdots & J_{2, n} \\
\vdots & \vdots & \ddots & \vdots \\
J_{m, 1}+\alpha R_{m} & J_{m, 2} & \cdots & J_{m, n} \\
J_{m+1,1} & J_{m+1,2} & \cdots & J_{m+1, n} \\
\vdots & \vdots & \ddots & \vdots \\
J_{n, 1} & J_{n, 2} & \cdots & J_{n, n}
\end{array}\right]}_{X}\left[\begin{array}{c}
0 \\
0 \\
\vdots \\
0 \\
\Delta P^{*} \\
\vdots \\
0
\end{array}\right]}
\end{aligned}
$$

The active power and DC voltage deviations of VSC stations according to (5) are determined by:

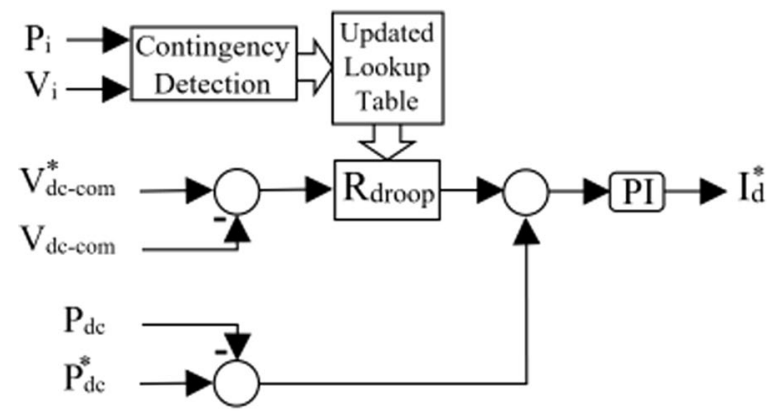

(a)

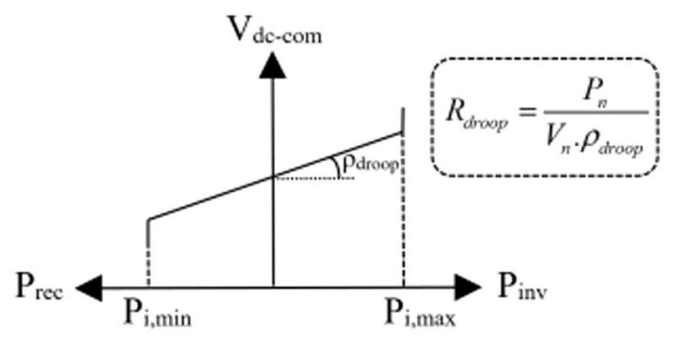

(b)

Fig. 2 a Block diagram of the proposed droop control; $\mathbf{b}$ the P-V characteristic curve

$$
\left\{\begin{array}{c}
\Delta V_{i}=\frac{1}{|X|} X_{i, m+1}^{A} \Delta P=\frac{1}{|X|} X_{m+1, i}^{C} \Delta P \\
=\frac{(-1)^{m+1+i} X_{m+1, i}^{M} \Delta P \quad(i=1: n)}{\sum_{i^{\prime}=1}^{n}(-1)^{i^{\prime}+1} X_{i^{\prime}, 1} X_{i^{\prime}, 1}^{M}} \quad(i=1: m) \\
\Delta P_{i}=-\alpha R_{i} \Delta V \quad
\end{array}\right.
$$

where $\mathrm{X}^{\mathrm{A}}, \mathrm{X}^{\mathrm{C}}$, and $\mathrm{X}^{\mathrm{M}}$ matrices refer to the adjugate matrix, cofactor matrix, and minor of $\mathrm{X}$, respectively. The constrained optimization problem is expressed by:

$$
\begin{aligned}
& \max \quad \Delta P^{*} \\
& \text { subject to } \\
& \Delta V_{i, \min } \leq \Delta V_{i} \leq \Delta V_{i, \max }(i=1: n) \\
& \Delta P_{i} \leq \Delta P_{i, \text { max }} \quad(i=1: m) \\
& R_{i}=R_{i, 0} \\
& 0 \leq \alpha R_{i} \leq R_{i, \max } \quad\left(i=k_{1}, k_{2}, \ldots, k_{j}\right)
\end{aligned}
$$


The following process is proposed to find the optimal droop coefficients related to the output power of OWFs:

1. The maximum allowable wind power considering the initial droop coefficients $\left(\mathrm{k}_{\mathrm{i}}=0\right)$ is computed by solving the problem (7).

2. If any power constraint is activated by the problem (7) solving process, the droop coefficient of its related converter is permitted to change.

3. If any voltage constraint is activated by the problem (7) solving process, the droop coefficient that minimizes (8) is permitted to change.

$$
\min \alpha\left(R_{i, \max }-R_{i, 0}\right)\left(R_{\max , 0} / R_{i, 0}\right)
$$

4. Problem (7) is modified based on updated droop constraints obtained from the 2nd and 3rd steps. Then, it is solved to find the new maximum allowable wind power and its corresponding optimal droop coefficients.

5. For a more accurate estimate, the constrained optimization problem (9) can be expressed based on updated droop constraints obtained from the 2nd step. It determines the optimal droop coefficients related to the specific wind power $\left(\Delta \mathrm{P}_{\text {spec }}\right)$ that is less than the maximum allowable power computed in the 3rd step. To increase accuracy of the look-up table, problem (9) should be solved with several specific wind powers (the higher they are, the more accurate it is).

$$
\begin{array}{ll}
\min \sum_{i=1}^{m}\left(\frac{R_{i}-R_{i, 0}}{R_{i, 0}}\right)^{2} & \\
\text { subject to } & \\
\Delta V_{i, \min } \leq \Delta V_{i} \leq \Delta V_{i, \max } & (i=1: n) \\
\Delta P_{i} \leq \Delta P_{i . m a x} & (i=1: m) \\
\Delta P_{m+1}=\Delta P_{\text {spec }} & \left(i=1: m ; i \neq k_{1}, k_{2}, \ldots, k_{j}\right) \\
R_{i}=R_{i, 0} & \left(i=k_{1}, k_{2}, \ldots, k_{j}\right)
\end{array}
$$

Steps 2-5 are repeated until all converters reach their ratings. In each iteration, the optimal droop coefficients related to the specific output power of OWFs are obtained. Finally, the optimal droop coefficients are approximated by interpolation as a function of wind power changes.

\subsection{Converter outage}

With the outage of the jth converter, the system equations are expressed by:

$$
\begin{aligned}
& \left\{\left.\begin{array}{l}
\Delta P_{i}=-\alpha R_{i} \Delta V_{1} \\
\Delta P_{i}=\sum_{j=1}^{n} J_{i, j} \Delta V_{j}
\end{array}\right|_{i=1: n} \stackrel{\Delta P_{j}=-P_{j}}{\stackrel{R_{i}=0}{\longrightarrow} i \geq m+1}\right. \\
& {\left[\begin{array}{c}
\Delta V_{1} \\
\vdots \\
\Delta V_{j} \\
\vdots \\
\Delta V_{m} \\
\Delta V_{m+1} \\
\vdots \\
\Delta V_{n}
\end{array}\right]=\underbrace{\left[\begin{array}{cccc}
J_{1,1}+\alpha R_{1} & J_{1,2} & \cdots & J_{1, n} \\
\vdots & \vdots & \ddots & \vdots \\
J_{j, 1} & J_{j, 2} & \cdots & J_{j, n} \\
\vdots & \vdots & \ddots & \vdots \\
J_{m, 1}+\alpha R_{m} & J_{m, 2} & \cdots & J_{m, n} \\
J_{m+1,1} & J_{m+1,2} & \cdots & J_{m+1, n} \\
\vdots & \vdots & \ddots & \vdots \\
J_{n, 1} & J_{n, 2} & \cdots & J_{n, n}
\end{array}\right]}_{X}\left[\begin{array}{c}
0 \\
\vdots \\
-P_{j} \\
\vdots \\
0 \\
0 \\
\vdots \\
0
\end{array}\right]}
\end{aligned}
$$

where $P_{j}$ refers to the active power of the jth converter before its outage. The DC voltage and active power deviations of VSC stations according to (10) and the constrained optimization problem are respectively determined by:

$$
\left\{\begin{array}{c}
\Delta V_{i}=\frac{1}{|X|} X_{i, j}^{A}\left(-P_{j}\right)=\frac{1}{|X|} X_{j, i}^{C}\left(-P_{j}\right) \\
=\frac{(-1)^{j+i} X_{j, i}^{M}}{\sum_{i^{\prime}=1}^{n}(-1)^{i^{\prime}+1} X_{i^{\prime}, 1} X_{i^{\prime}, 1}^{M}}\left(-P_{j}\right)(i=1: n ; i \neq j) \\
\Delta P_{i}=-\alpha R_{i} \Delta V_{1}(i=1: m ; i \neq j)
\end{array}\right.
$$

and

$$
\begin{array}{ll}
\min \sum_{\substack{i=1 \\
i \neq j}}^{m}\left(\frac{R_{i}-R_{i, 0}}{R_{i, 0}}\right)^{2} & \\
\text { subject to } & \\
\Delta V_{i, \text { min }} \leq \Delta V_{i} \leq \Delta V_{i, \text { max }} & (i=1: n ; i \neq j) \\
\Delta P_{i} \leq \Delta P_{i, \max } & (i=1: m ; i \neq j) \\
R_{i}=R_{i, 0} & \left(i=k_{1}, k_{2}, \ldots, k_{j-1} ; i \neq j\right) \\
0 \leq \alpha R_{i} \leq R_{i, \max } & \left(i=1: m ; i \neq j, k_{1}, k_{2}, \ldots, k_{j-1}\right)
\end{array}
$$

$\left.k_{j}\right)$ The following process is proposed to find the optimal droop coefficients during the jth converter outage:

1. Problem (12) is solved assuming that all droop coefficients are permitted to change $\left(\mathrm{k}_{\mathrm{i}}=0\right)$.

2. If any power constraints are activated by the problem (12) solving process, the droop coefficients of their related converters are still permitted to change.

3. If any voltage constraint is activated by the problem (12) solving process, the droop coefficient that minimizes (8) is still allowed to change.

4. The rest of the droop coefficients are considered equal to their initial value $\left(\mathrm{R}_{\mathrm{i}, 0}\right)$.

5. Problem (12) is modified based on updated droop constraints obtained from the 2nd, 3rd and 4th steps. 
6. If the problem (12) solving process cannot find an optimal solution, the $(\lambda+1)$ th droop coefficient that minimizes (8) is also allowed to change $(\lambda=$ iteration number).

Steps 5, 6 are repeated until problem (12) can find an optimal solution. The 1st converter outage deteriorates the reliable operation of the MTDC system because of missing common voltage feedback $\left(\Delta \mathrm{V}_{1}\right)$. Accordingly, the system equations in (10) should also be defined based on another voltage feedback (e.g., $\Delta \mathrm{V}_{2}$ ) to maintain stability during the 1 st converter outage.

\subsection{DC line disconnection}

By disconnecting any DC line (e.g., $\mathrm{T}_{\mathrm{j}, \mathrm{m}}$ ), the system equations are expressed by:

$$
\begin{gathered}
\left\{\begin{array}{c}
\Delta P_{i}=-\alpha R_{i} \Delta V_{1} \\
\Delta P_{i}=\sum_{j=1}^{n} J_{i, j}^{*} \Delta V_{j}+\sum_{j=1}^{n} J_{i, j}^{\prime} \Delta Y_{j, i}^{T}
\end{array} \mid \begin{array}{c}
\Delta V_{i=1: n} \\
R_{i}=0 \\
\vdots \\
\Delta V_{j} \\
\vdots \\
\Delta V_{m} \\
\Delta V_{m+1} \\
\vdots \\
\Delta V_{n}
\end{array}\right]=\underbrace{\left[\begin{array}{ccc}
J_{1,1}^{*}+\alpha R_{1} & \cdots & J_{1, n}^{*} \\
\vdots & \ddots & \vdots \\
J_{j, 1}^{*}+\alpha R_{j} & \cdots & J_{j, n}^{*} \\
\vdots & \ddots & \vdots \\
J_{m, 1}^{*}+\alpha R_{m} & \cdots & J_{m, n}^{*} \\
J_{m+1,1}^{*} & \cdots & J_{m+1, n}^{*} \\
\vdots & \ddots & \vdots \\
J_{n, 1}^{*} & \cdots & J_{n, n}^{*}
\end{array}\right]}_{X=m+1}\left[\begin{array}{c}
0 \\
\vdots \\
-\left(J_{j, j}^{\prime}-J_{j, m}^{\prime}\right) Y_{j, m} \\
\vdots \\
-\left(J_{m, m}^{\prime}-J_{m, j}^{\prime}\right) Y_{m, j} \\
0 \\
\vdots \\
0
\end{array}\right]
\end{gathered}
$$

where $\mathrm{J}^{*}$ and $\mathrm{J}^{\prime}$ are the modified Jacobin matrix and the derivative of the power flow equations with respect to DC line admittances. They are obtained by:

$$
\left\{\begin{array}{c}
J^{\prime}=\left[\begin{array}{ccc}
\partial P_{1} / \partial Y_{1,1} & \ldots & \partial P_{1} / \partial Y_{1, n} \\
\vdots & \ddots & \vdots \\
\partial P_{n} / \partial Y_{n, 1} & \ldots & \partial P_{n} / \partial Y_{n, n}
\end{array}\right]=V \cdot V^{T} \\
J^{*}=\operatorname{diag}(V) Y^{*}+\operatorname{diag}\left(Y^{*} V\right)
\end{array}\right.
$$

where $\mathrm{Y}^{*}$ refers to the modified admittance matrix that is affected by DC line disconnection. The active power and DC voltage deviations of VSC stations and the constrained optimization problem are determined respectively by:

$$
\left\{\begin{aligned}
\Delta V_{i} & =\frac{-1}{|X|}\left(X_{i, j}^{A}\left(J_{j, j}^{\prime}-J_{j, m}^{\prime}\right) Y_{j, m}+X_{i, m}^{A}\left(J_{m, m}^{\prime}-J_{j, m}^{\prime}\right) Y_{j, m}\right) \\
= & \frac{-1}{|X|}\left(X_{j, i}^{C}\left(J_{j, j}^{\prime}-J_{j, m}^{\prime}\right) Y_{j, m}+X_{m, i}^{C}\left(J_{m, m}^{\prime}-J_{j, m}^{\prime}\right) Y_{j, m}\right) \\
= & \frac{(-1)^{j+i+1} X_{j, i}^{M}\left(J_{j, j}^{\prime}-J_{j, m}^{\prime}\right)}{\sum_{i^{\prime}=1}^{n}(-1)^{i^{\prime}+1} X_{i^{\prime}, 1} X_{i^{\prime}, 1}^{M}}\left(Y_{j, m}\right) \\
& +\frac{(-1)^{m+i+1} X_{m, i}^{M}\left(J_{m, m}^{\prime}-J_{j, m}^{\prime}\right)}{\sum_{i^{\prime}=1}^{n}(-1)^{i^{\prime}+1} X_{i^{\prime}, 1} X_{i^{\prime}, 1}^{M}}\left(Y_{j, m}\right) \quad(i=1: n ; i \neq j) \\
\Delta P_{i} & =-\alpha R_{i} \Delta V \quad(i=1: m ; i \neq j)
\end{aligned}\right.
$$

and

$$
\begin{array}{ll}
\min \sum_{i=1}^{m}\left(\frac{R_{i}-R_{i, 0}}{R_{i, 0}}\right)^{2} & \\
\text { subject to } & \\
\Delta V_{i, \text { min }} \leq \Delta V_{i} \leq \Delta V_{i, \text { max }} & (i=1: n) \\
\Delta P_{i} \leq \Delta P_{i . \max } & (i=1: m) \\
R_{i}=R_{i, 0} & \left(i=k_{1}, k_{2}, \ldots, k_{j}\right) \\
0 \leq \alpha R_{i} \leq R_{i, \max } & \left(i=1: m ; i \neq k_{1}, k_{2}, \ldots, k_{j}\right)
\end{array}
$$

If any converter is separated from the MTDC system because of DC line disconnection, its related power and voltage constraints are ignored. The constrained optimization problem (16) can be solved according to the proposed process in Sect. 3.2 to obtain the optimal droop coefficients during DC line disconnection. It should be noted that during sequential disturbances, system equations are modified by combining of (5), (10), and (13) based on disturbances that occur.

\section{Results and discussion}

The proposed droop-based control strategy is implemented on a bipolar 4-terminal VSC-MTDC system in the MATLAB/Simulink R2016a environment. It consists of three onshore AC grids (VSC1, VSC2, and VSC3) and an offshore wind farm (VSC4), as shown in Fig. 3. VSC1, VSC2, and VSC3 operate in droop control mode, while VSC4 operates at AC voltage and in constant frequency control mode.

The PI model of DC lines, detailed model of VSCs (including IGBT and reverse parallel diode), high-pass filters, DC filters (to eliminate dominant harmonics), and sinusoidal pulse width modulation (SPWM) technique are implemented in the simulation. The central controller uses a high bandwidth communication structure to collect online information from the VSC stations to determine the look-up table and detect disturbances. It then applies the optimal droop coefficients to the converters based on operating conditions. The sequential 
quadratic programming (SQP) method is used to solve the proposed constrained optimization problems, as it has good performance in solving large-scale linear and nonlinear optimization problems [47]. Table 1 shows the parameters of the VSC-MTDC system, while the initial steady-state conditions of the MTDC system are given in Table 2.

The proposed control strategy is compared with three conventional droop-based control methods to validate its effectiveness, i.e., fixed, adaptive based on available headroom (P-based) [27], and adaptive based on the tradeoff between power and voltage (P-V-based) [33]. The proposed droop coefficients in these methods are the basis of the first control layer in most control methods.

The contingencies are set as follow:

1. $t=2 \mathrm{~s}$, increasing the output power of OWFs to $1450 \mathrm{MW}$.

2. $t=4 \mathrm{~s}$, decreasing the output power of OWFs to $1200 \mathrm{MW}$.

3. $\mathrm{t}=6 \mathrm{~s}$, disconnecting L34.

4. $t=8 \mathrm{~s}, \mathrm{VSC} 3$ station outage.

The transient conditions are not considered during DC line disconnection or converter outage in this paper. The proposed look-up table for the initial operation of the system is shown in Fig. 4, while the optimal droop coefficients during the 1st and 2nd contingencies are determined accordingly.

The power sharing and DC voltages of VSC stations in different control methods during the mentioned disturbances are shown in Figs. 5 and 6, respectively. As seen in Fig. 5a, with fixed droop coefficients without considering the operating conditions of the system, the active power of VSC2 (P2) exceeds its rating by $7.5 \%$ and $23 \%$ during the 1 st and 4th disturbances, respectively. Figure $5 \mathrm{~b}, \mathrm{c}$ also indicate that although the active powers of VSC stations remain within their ratings, optimal power sharing does not occur with either P-based or P-V-based

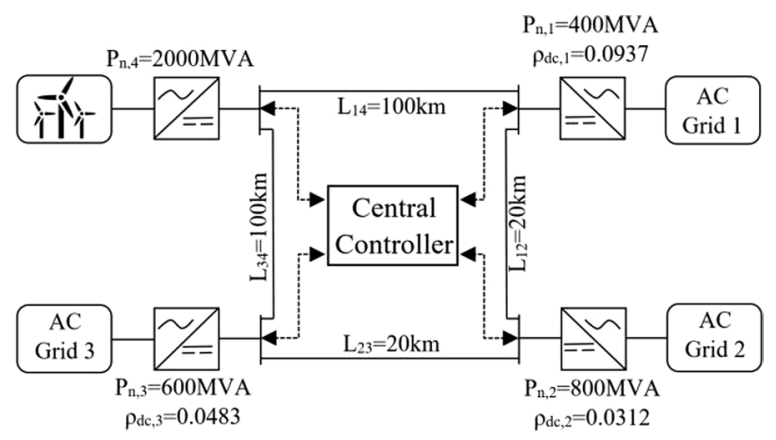

Fig. 3 Bipolar 4-terminal VSC-MTDC test system
Table 1 Parameters of the VSC-MTDC test system

\begin{tabular}{ll}
\hline Line voltage of AC grid (rms) & $370(\mathrm{kV})$ \\
Equivalent resistance of AC system & $0.08(\Omega)$ \\
Equivalent inductance of AC system & $0.025(\mathrm{H})$ \\
Fundamental frequency & $50(\mathrm{~Hz})$ \\
Carrier frequency as multiple of fundamental & 27 \\
Limit of the DC voltage deviation & $5 \%$ \\
Phase reactor & $0.15(\mathrm{p} . \mathrm{u})$. \\
Transformer & $2000(\mathrm{MVA})$, \\
& $370 / 320(\mathrm{kV}), \mathrm{YgD}$, \\
& $0.15(\mathrm{p} . \mathrm{u})$. \\
Unit resistance of the DC line & $0.4(\Omega / \mathrm{km})$ \\
Unit inductance of the DC line & $0.45(\mathrm{mH} / \mathrm{km})$ \\
Unit capacitance of the DC line & $23(\mu \mathrm{F} / \mathrm{km})$ \\
Rated DC voltage & $\pm 320(\mathrm{kV})$ \\
$\mathrm{K}_{\text {l }}$ and $\mathrm{K}_{\mathrm{p}}$ of inner control loop & $6,0.6$
\end{tabular}

adaptive droop controls. This is because their droop coefficients are defined only based on maintaining converters within their ratings, without considering optimal power sharing. With the proposed control, Fig. 5d shows that the active powers of VSC stations are within their ratings, and optimal power sharing occurs immediately after contingency detection, without needing a secondary control layer.

Figure 6 indicates that the maximum voltage deviations from the rated DC voltage with fixed droop control, P-based adaptive droop control, $\mathrm{P}-\mathrm{V}$-based adaptive droop control, and the proposed adaptive droop control are $4.65 \%, 12.44 \%, 7.38 \%$, and $3.88 \%$, respectively. They occur in the VSC4 station during the 4th disturbance. Figure $6 \mathrm{~b}$ indicates that with $\mathrm{P}$-based adaptive droop control, the DC voltages of VSC1, VSC2, and VSC4 exceed their limits by $4.6 \%, 4.26 \%$, and $7.08 \%$ respectively during the 4th disturbance, as the voltage constraints are ignored in determining the droop coefficients. In contrast, with P-V-based adaptive droop control, Fig. 6c shows that by considering the impact of voltage on droop coefficients, the DC voltages of VSC1, VSC2, and VSC3 remain within their limits. However, the DC voltage of other converters without droop control mode cannot be guaranteed, e.g., the DC voltage of VSC4 with constant power mode exceeds its limit by $2.26 \%$ under the 4 th disturbance. With the proposed control, Fig. $6 \mathrm{~d}$ shows that

Table 2 Initial steady-state conditions of the MTDC system

\begin{tabular}{lllll}
\hline Terminal no & VSC1 & VSC2 & VSC3 & VSC4 \\
\hline Power (MW) & 100 & 600 & 291.1 & 1000 \\
DC Voltage (kV) & 640 & 639.23 & 640.34 & 645.39 \\
\hline
\end{tabular}




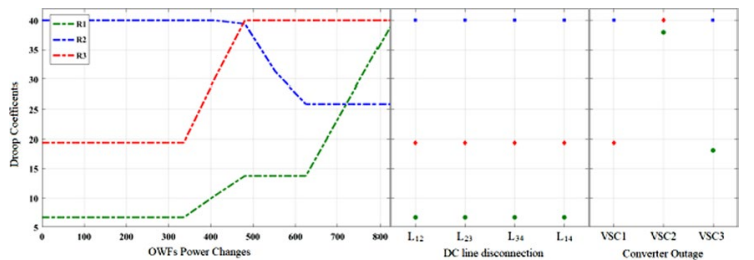

Fig. 4 The look-up table for the initial operating conditions

the DC voltages of all VSC stations remain within their limits due to consideration of the voltage constraints in optimal droop coefficients.

To maintain system stability when the converters exceed their limits (e.g., Figs. 5a, 6b, c), wind power curtailment is required. The proposed control method overcomes this drawback by minimizing DC voltage deviation and maintaining converters within their ratings. Therefore, the maximum output power of OWFs can be used without any curtailment.

The impact of system linearization error on determining droop coefficients is trivial such that it can be ignored compared to the reduction of computational time. The maximum relative errors of DC voltage and active power occur at VSC4 $\left(\delta_{\mathrm{V} 4}=0.096 \%\right)$ and VSC2 $\left(\delta_{\mathrm{P} 2}=0.921 \%\right)$ under the 4th disturbance.

Detailed simulation results of power sharing ratios amongst VSC1, VSC2, and VSC3 during the disturbances are shown in Table 3.

The initial optimal power sharing ratios between VSC1, VSC2, and VSC3 are 1, 6, and 2.91. Such ratios can neither be kept in fixed droop control because local voltage feedback makes power sharing dependent on DC line resistances, nor with $\mathrm{P}$-based and $\mathrm{P}-\mathrm{V}$-based adaptive droop control because of the influence of the available headroom of converters on droop coefficients. However, they are retained with the proposed control strategy except when converters reach their limits, such as during the 1st and 4th disturbances. In these conditions, the power sharing ratios have the minimum deviations from the initial values.

\section{Conclusion}

This paper has proposed a novel centralized droop-based control strategy to maintain the optimal operation of MTDC systems immediately in post-contingency conditions. The method determines the look-up table containing optimal droop coefficients before the occurrence of disturbances and is based on the prediction of linearized system equations around the operating point in various contingencies such as wind power changes, DC line

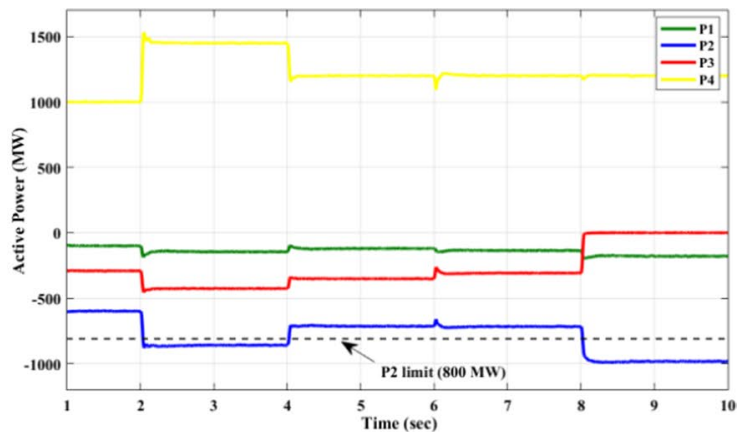

(a)

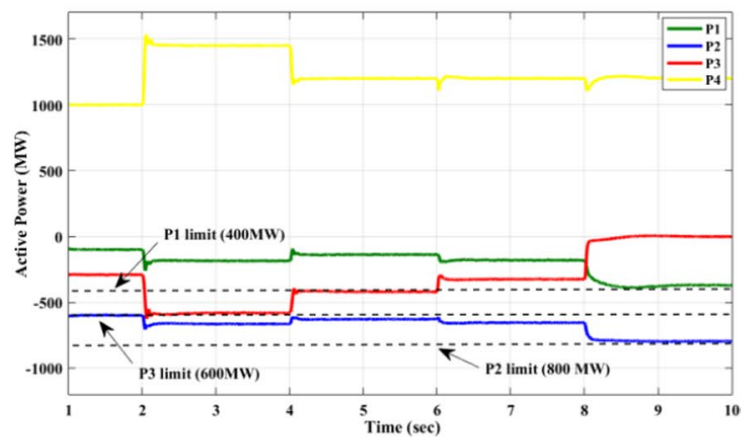

(b)

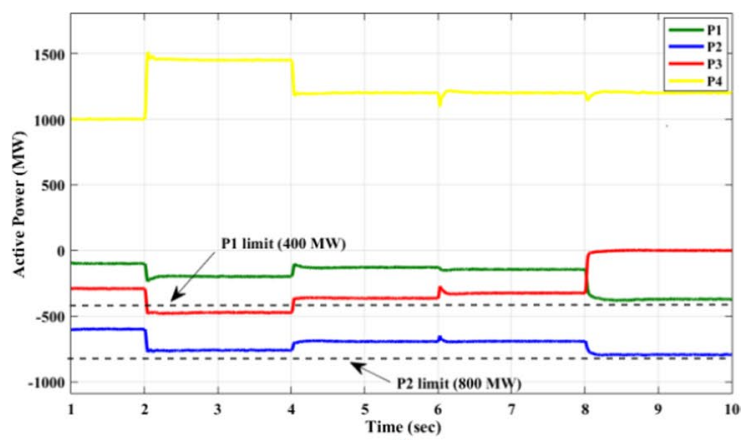

(c)

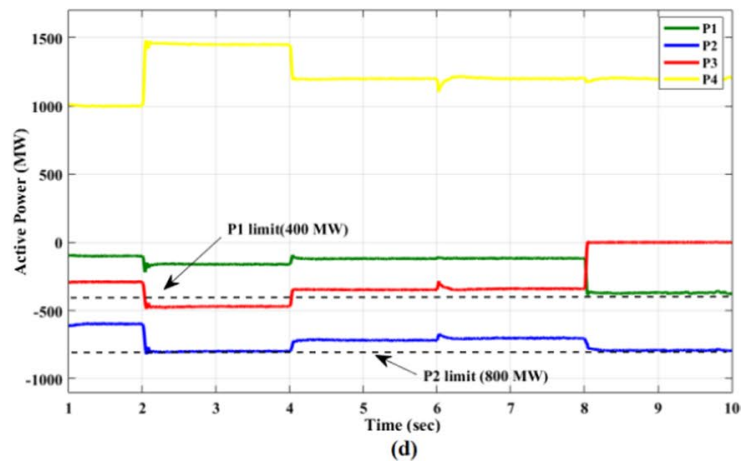

Fig. 5 Power sharing in different control methods: a fixed droop control. b P-based adaptive droop control. c P-V-based adaptive droop control. $\mathbf{d}$ proposed adaptive droop control

disconnection, and converter outage. Stability constraints and converter limitations have also been considered in the determination of optimal droop coefficients. 


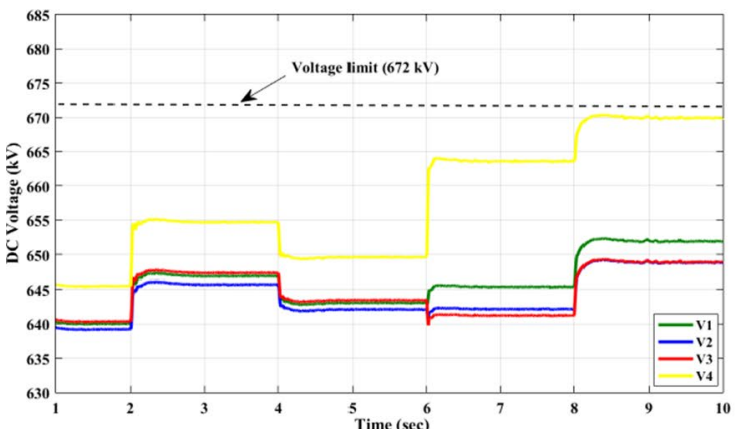

(a)

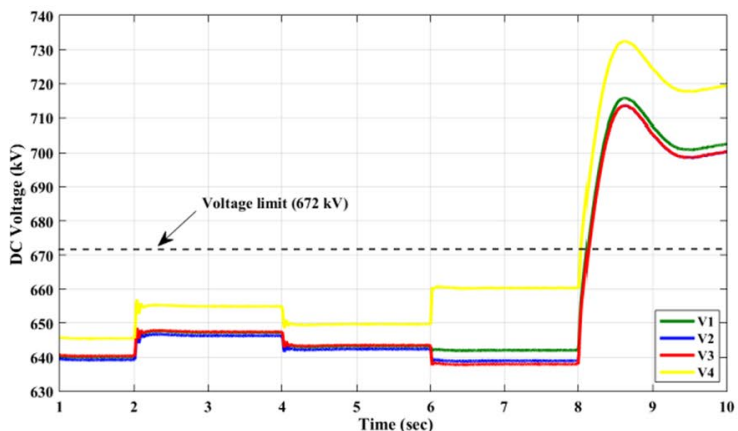

(b)
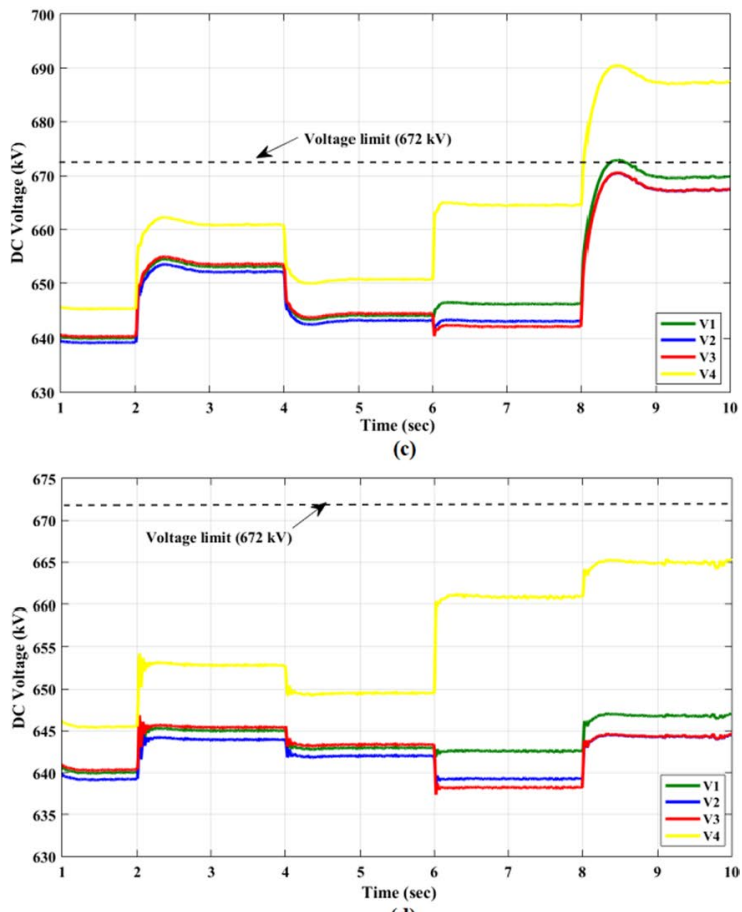

(d)

Fig. 6 DC voltages of VSC stations in different control methods: a fixed droop control. b P-based adaptive droop control. c P-V-based adaptive droop control. $\mathbf{d}$ proposed adaptive droop control

The proposed look-up table has been implemented in the primary control layer, and thus the need for a secondary control layer in terms of optimal operation has
Table 3 Power sharing ratios amongst onshore AC grids

\begin{tabular}{lllll}
\hline Method & Disturbances & VSC1 & VSC2 & VSC3 \\
\hline Fixed droop control & 1st & 1 & 5.71 & 2.97 \\
& 2nd & 1 & 5.7 & 2.97 \\
& 3rd & 1 & 3.29 & 0.47 \\
& 4 th & 1 & 4.85 & NA \\
P-based adaptive droop control & 1st & 1 & 0.76 & 3.38 \\
& 2nd & 1 & 0.76 & 3.38 \\
& 3rd & 1 & 0.68 & 0.42 \\
P-V-based adaptive droop control & 1st & 1 & 0.72 & NA \\
& 2nd & 1 & 1.62 & 1.83 \\
& 3rd & 1 & 3.23 & 2.49 \\
& 4th & 1 & 5.98 & 2.9 \\
Proposed adaptive droop control & 1st & 1 & 3.72 & NA \\
& 2nd & 1 & 6 & 2.91 \\
& 3rd & 1 & 6 & 2.91 \\
& 4th & 1 & 0.71 & NA \\
\hline
\end{tabular}

been eliminated. The simulation results illustrate that optimal power sharing and minimum DC voltage deviations have occurred immediately during small and large disturbances, while all converters (in any control mode) have been preserved within their limits. The proposed method has also led to the maximum utilization of the output power of OWFs without any curtailment during more disturbances and this compares well with traditional droop methods.

Acknowledgements

Not applicable.

Authors' contributions

Both authors read and approved the final manuscript.

\section{Funding}

Not applicable.

Availability of data and materials

Not applicable.

\section{Declaration}

\section{Competing interests}

The authors declare that they have no known competing financial interests or personal relationships that could have appeared to influence the work reported in this paper.

Received: 11 March 2021 Accepted: 19 January 2022

Published online: 28 January 2022

\section{References}

1. Hertem, D. V., Gomis-Bellmunt, O., \& Liang, J. (2017). HVDC grids: For offshore and supergrid of the future. Wiley-IEEE Press.

2. Abu-Elanien, A. E. B., Abdel-Khalik, A. S., \& Massoud, A. M. (2021). Multiterminal HVDC system with offshore wind farms under anomalous 
conditions: Stability assessment. IEEE Access, 9, 92661-92675. https://doi. org/10.1109/ACCESS.2021.3092696

3. Chachar, F. A., Bukhari, S. S. H., Mangi, F. H., Macpherson, D. E., Harrison, G. P., Bukhsh, W., \& Ro, J. (2019). Hierarchical control implementation for meshed AC/multi-terminal DC grids with offshore windfarms integration. IEEEAccess, 7, 142233-142245. https://doi.org/10.1109/ACCESS.2019. 2944718

4. Ryndzionek, R., \& Sienkiewicz, L. (2020). Evolution of the HVDC-link connecting offshore wind farms to onshore power systems. Energies. https:// doi.org/10.3390/en13081914

5. Sinsel, S. R., Riemke, R. L., \& Hoffmann, V. H. (2020). Challenges and solution technologies for the integration of variable renewable energy sources-A review. Renewable Energy, 145, 2271-2285. https://doi.org/10. 1016/j.renene.2019.06.147

6. Rodriguez, P., \& Rouzbehi, K. (2017). Multi-terminal DC grids: Challenges and prospects. Journal of Modern Power Systems and Clean Energy, 5, 515-523. https://doi.org/10.1007/s40565-017-0305-0

7. Pierri, E., Binder, O., Hemdan, N. G., \& Kurrat, M. (2017). Challenges and opportunities for a European HVDC grid. Renewable and Sustainable Energy Reviews, 70, 427-456. https://doi.org/10.1016/j.rser.2016.11.233

8. Taiarol, P. V. I., MacPhail, G. A., Pathirana, V. S., \& Mampaey, B. (2014). The atlantic wind connection-Building the foundation for offshore wind energy. In CIGRÉ Belgium conference, Brussels (Belgium).

9. Acha, E., Roncero-Sánchez, P., de la Villa-Jaen, A., Castro, L. M., \& Kazemtabrizi, B. (2019). VSC-FACTS-HVDC: Analysis, modelling and simulation in power grids. Wiley.

10. Fu, Y., Wang, C., Tian, W., \& Shahidehpour, M. (2016). Integration of largescale offshore wind energy via VSC-HVDC in day-ahead scheduling. IEEE Transactions on Sustainable Energy, 7(2), 535-545. https://doi.org/10.1109/ TSTE.2015.2499742

11. Wang, Z., Li, K., Ren, J., Sun, L., Zhao, J., Liang, Y., Lee, W., Ding, Z., \& Sun, Y. (2015). A coordination control strategy of voltage source converter-based MTDC for offshore wind farms. IEEE Transactions on Industry Applications, 51(4), 2743-2752. https://doi.org/10.1109//AS.2014.6978377

12. Irnawan, R. (2020). Planning and control of expandable multi-terminal VSCHVDC transmission systems. Springer Theses.

13. Chaudhuri, N., Chaudhuri, B., Majumder, R., \& Yazdani, A. (2014). Multiterminal direct-current grids: Modeling, analysis, and control (pp. 153-166). Wiley-IEEE Press.

14. Li, X., Yuan, Z., Fu, J., Wang, Y., Liu, T., \& Zhu, Z. (2014). Nanao multi-terminal VSC-HVDC project for integrating large-scale wind generation. In IEEE PES general meeting|conference \& exposition, pp. 1-5. https://doi.org/10.1109/ PESGM.2014.6939123

15. Bianchi, F. D., Domínguez-García, J. L., \& Gomis-Bellmunt, O. (2016). Control of multi-terminal HVDC networks towards wind power integration: A review. Renewable and Sustainable Energy Reviews, 55, 1055-1068. https:// doi.org/10.1016/j.rser.2015.11.024

16. Cheng, Zh. P., Wang, Y. F., Li, Zh. W., \& Gao, J. F. (2019). DC voltage margin adaptive droop control strategy of VSC-MTDC systems. The Journal of Engineering, IET, 2019(16), 1783-1787. https://doi.org/10.1049/joe.2018. 8695

17. Beerten, J., Cole, S., \& Belmans, R. (2014). Modeling of multi-terminal VSC HVDC systems with distributed DC voltage control. IEEE Transactions on Power Systems, 29(1), 34-42. https://doi.org/10.1109/TPWRS.2013.22792 68

18. Simiyu, P., Xin, A., Bitew, G. T., Shahzad, M., Kunyu, W., \& Tuan, L. K. (2019). Review of the DC voltage coordinated control strategies for multiterminal VSC-MVDC distribution network. The Journal of Engineering, IET, 2019(16), 1462-1468. https://doi.org/10.1049/joe.2018.8841

19. Rouzbehi, K., Miranian, A., Candela, J. I., Luna, A., \& Rodriguez, P. (2015). A generalized voltage droop strategy for control of multi-terminal DC grids. IEEE Transactions on Industry Applications, 51(1), 607-618. https://doi.org/ 10.1109/TIA.2014.2332814

20. Beerten, J., \& Belmans, R. (2013). Analysis of power sharing and voltage deviations in droop-controlled DC grids. IEEE Transaction on Power System, 28(4), 4588-4597. https://doi.org/10.1109/TPWRS.2013.2272494

21. Wang, W., Barnes, M., \& Marjanovic, O. (2018). Stability limitation and anaIytical evaluation of voltage droop controllers for VSC MTDC. CSEE Journal of Power and Energy Systems, 4(2), 238-249. https://doi.org/10.17775/ CSEEJPES.2016.00670
22. Aragüés-Peñalba, M., Egea-Alvarez, A., Arellano, S. G., \& Gomis-Bellmunt, O. (2014). Droop control for loss minimization in HVDC multi-terminal transmission systems for large offshore wind farms. Electric Power Systems Research, 112, 48-55. https://doi.org/10.1016/j.epsr.2014.03.013

23. Li, H., Liu, C., Li, G., \& Iravani, R. (2017). An enhanced DC voltage droopcontrol for the VSC-HVDC grid. IEEE Transaction on Power System, 32(2), 1520-1527. https://doi.org/10.1109/TPWRS.2016.2576901

24. Sayed, S. S., \& Massoud, A. M. (2021). General classification and comprehensive performance assessment of multi-objective DC voltage control in multi-terminal HVDC networks. IEEE Access, 9, 34454-34474. https://doi. org/10.1109/ACCESS.2021.3060935

25. Gao, Y., \& Ai, Q. (2018). Distributed multi-agent control for combined AC/ DC grids with wind power plant clusters. IET Generation, Transmission \& Distribution, 12(3), 670-677. https://doi.org/10.1049/iet-gtd.2017.0689

26. Berggren, B., Lindén, K., \& Majumder, R. (2015). DC grid control through the pilot voltage droop concept methodology for establishing droop constants. IEEE Transaction on Power System, 30(5), 2312-2320. https://doi. org/10.1109/TPWRS.2014.2360585

27. Chaudhuri, N. R., \& Chaudhuri, B. (2013). Adaptive droop control for effective power sharing in multi-terminal DC (MTDC) grids. IEEE Transaction on Power System, 28(1), 21-29. https://doi.org/10.1109/TPWRS.2012.2203390

28. Li, B., Li, Q., Wang, Y., Wen, W., Li, B., \& Xu, L. (2020). A novel method to determine droop coefficients of DC voltage control for VSC-MTDC system. IEEE Transactions on Power Delivery, 35(5), 2196-2211. https://doi.org/ 10.1109/TPWRD.2019.2963447

29. Abdel-Khalik, A. S., Massoud, A. M., Elserougi, A. A., \& Ahmed, Sh. (2013). Optimum power transmission-based droop control design for multiterminal HVDC of offshore wind farms. IEEE Transactions on Power Systems, 28(3), 3401-3409. https://doi.org/10.1109/TPWRS.2013.2238685

30. Prieto-Araujo, E., Egea-Alvarez, A., Fekriasl, S., \& Gomis-Bellmunt, O. (2016). DC voltage droop control design for multi-terminal HVDC systems considering AC and DC grid dynamics. IEEE Transaction on Power Delivery, 31(2), 575-585. https://doi.org/10.1109/TPWRD.2015.2451531

31. Dong, H., Liu, K., Su, M., Zou, W., \& Ma, X. (2021). Droop control design of MTDC systems with large-scale renewable integration based on ANFIS. In 20213 rd Asia energy and electrical engineering symposium (AEEES), pp. 650-654. https://doi.org/10.1109/AEEES51875.2021.9403080

32. Chen, X., Wang, L., Sun, H., \& Chen, Y. (2017). Fuzzy logic based adaptive droop control in multi-terminal HVDC for wind power integration. IEEE Transactions on Energy Conversion, 32(3), 1200-1208. https://doi.org/10. 1109/TEC.2017.2697967

33. Wang, Y., Wen, W., Wang, Ch., Liu, H., Zhan, X. \& Xiao, X. (2019). Adaptive voltage droop method of multi-terminal VSC-HVDC systems for DC voltage deviation and power sharing. IEEE Transaction Power Delivery, 34(1), 169-176. https://doi.org/10.1109/TPWRD.2018.2844330

34. Satish Kumar, A., \& Prasad Padhy, B. (2019). Adaptive droop control strategy for autonomous power sharing and DC voltage control in wind farm-MTDC grids. IET Renewable Power Generation, 13(16), 3180-3190. https://doi.org/10.1049/iet-rpg.2019.0027

35. Shinoda, K., Benchaib, A., Dai, J., \& Guillaud, X. (2021). Over- and undervoltage containment reserves for droop-based primary voltage control of MTDC grids. IEEE Transactions on Power Delivery. https://doi.org/10.1109/ TPWRD.2021.3054183

36. Kirakosyan, A., El-Saadany, E. F., Moursi, M. S. E., Acharya, S., \& Hosani, K. A. (2018). Control approach for the multi-terminal HVDC system for the accurate power sharing. IEEE Transaction on Power System, 33(4), 4323-4334. https://doi.org/10.1109/TPWRS.2017.2786702

37. Mei, M., Wang, P., Che, Y., \& Xing, Ch. (2021). Adaptive coordinated control strategy for multi-terminal flexible DC transmission systems with deviation control. Journal of Power Electronics, 21, 724-734. https://doi.org/10. 1007/s43236-021-00219-7

38. Abdelwahed, M. A., \& El-Saadany, E. F. (2017). Power sharing control strategy of multi-terminal VSC-HVDC transmission systems utilizing adaptive voltage droop. IEEE Transactions on Sustainable Energy, 8(2), 605-615. https://doi.org/10.1109/TSTE.2016.2614223

39. Rouzbehi, K., Miranian, A., Luna, A., \& Rodriguez, P. (2014). DC voltage control and power sharing in multi-terminal DC grids based on optimal DC power flow and voltage-droop strategy. IEEE Journal of Emerging and Selected Topics in Power Electronics, 2(4), 1171-1180. https://doi.org/10. 1109/JESTPE.2014.2338738 
40. Yadav, O., Prasad, Sh., Kishor, N., Negi, R., \& Purwar, Sh. (2020). Controller design for MTDC grid to enhance power sharing and stability. IET Generation, Transmission \& Distribution, 14(12), 2323-2332. https://doi.org/10. 1049/iet-gtd.2019.0880

41. Wang, Z., He, J., Xu, Y., \& Zhang, F. (2020). Distributed control of VSC-MTDC systems considering tradeoff between voltage regulation and power sharing. IEEE Transactions on Power Systems, 35(3), 1812-1821. https://doi. org/10.1109/TPWRS.2019.2953044

42. Akhter, F. (2015). Secure optimal operation and control of integrated AC/ MTDC meshed grids. Ph.D. thesis, University of Edinburgh, Scotland.

43. Nazari, M. (2017). Control and planning of multi-terminal HVDC transmission systems. Ph.D. thesis, Dept. Elect. Eng., KTH Royal Institute of Technology, Sweden.

44. Zhao, X., \& Li, K. (2015). Droop setting design for multi-terminal HVDC grids considering voltage deviation impacts. Electric Power Systems Research, 123, 67-75. https://doi.org/10.1016/j.epsr.2015.01.022

45. Kirakosyan, A., El-Saadany, E. F., Moursi, M. S. E., \& Hosani, K. A. (2018). DC voltage regulation and frequency support in pilot voltage droop controlled multi terminal HVDC systems. IEEE Transactions on Power Delivery, 33(3), 1153-1164. https://doi.org/10.1109/TPWRD.2017.2759302

46. Che, Y., Jia, J., Zhu, J., Li, X., Lv, Z., \& Li, M. (2019). Stability evaluation on the droop controller parameters of multi-terminal DC transmission systems using small-signal model. IEEE Access, 7, 103948-103960. https://doi.org/ 10.1109/ACCESS.2019.2931118

47. Andrei, N. (2017). A SQP algorithm for large-scale constrained optimization: SNOPT. In N. Andrei (Ed.), Continuous nonlinear optimization for engineering applications in GAMS technology: Springer optimization and its applications (Vol. 121, pp. 317-330). Springer. https://doi.org/10.1007/ 978-3-319-58356-3_15

\section{Submit your manuscript to a SpringerOpen ${ }^{\odot}$ journal and benefit from:}

- Convenient online submission

- Rigorous peer review

- Open access: articles freely available online

- High visibility within the field

- Retaining the copyright to your article

Submit your next manuscript at $\boldsymbol{\nabla}$ springeropen.com 